\title{
Analysis On The Method Of Highway Carbon Sink Forest
}

\author{
Dongxiang Cheng ${ }^{1,2, a}$, Bin Liu ${ }^{2,3, b}$, Jing Chen ${ }^{1,2, c}$ \\ ${ }^{1}$ Nanjing Vocational Institute of Transport Technology, Nanjing 211188 China \\ ${ }^{2}$ Jiangsu Engineering Technology Research Center for Energy Conservation and Emission \\ Reduction of Transportation; Nanjing 211188 China \\ ${ }^{3}$ Hohai University, Nanjing 211100 China

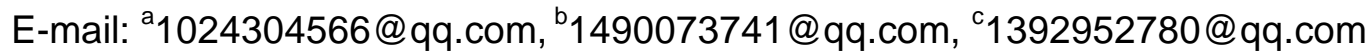

\begin{abstract}
Key words: Forest carbon sink, Carbon sink forest, Highway, Low carbon highway.
Abstract:In view of principle greening the basic design of the road in China, introducing the advanced concept of forest carbon sequestration, combined with afforestation project of carbon measurement and monitoring guidelines, to establish the quantitative and monitoring model of highway plant carbon sink. In order to improve the highway on both sides of the green plant quality, to carry out construction of forest carbon sinks, to achieve low carbon road and is of great importance to energy conservation and emissions reduction.
\end{abstract}

\section{Introduction}

With the rapid development of economy, more and more pollution is produced, questions but also to the more serious. According to statistics, the transportation sector is a key part of the carbon source, the 1990 World in the transport sector of the amount of carbon dioxide is 46.1 million tons, in 2008 the growth to 66 million tons, increased in the past 18 years of $43.2 \%$. Also China transportation amount of carbon dioxide emissions are also increasing year by year, In 2000 years of carbon dioxide emissions is 3.26 million tons, emissions of carbon dioxide in 2008 increased to 6.3 million tons, up 93.2\%. In transport carbon dioxide emissions, highway traffic accounted for large proportion, according to statistics, in 2008 highway traffic carbon emissions Volume accounted for the entire transport of carbon emissions of $73.4 \%[1]$. So on both sides of the highway carbon sink forest project implementation, the development of low-carbon roads, to create a low carbon, green traffic environment, to promote energy-saving emission reduction has far-reaching significance.

\section{The necessity of low carbon road built carbon sink forest development}

According to the <Transportation" 13th Five-Year "development plan>. highway transportation is the main part of the transportation industry, how to reduce the carbon emissions of highway transportation is important topic worthy of study. Development of low carbon road, reduce the level of greenhouse gases in the atmosphere, mainly include: to reduce carbon emissions, increase carbon sink. Reducing carbon emission sources requires the transportation sector to invest money to support advanced technologies to improve energy efficiency and reduce carbon emissions. Such as the promotion of green clean energy vehicles, using a zero emissions of new energy vehicles, but according to the current development situation of our country, the technical difficulty is big, need high cost, the difficulty of promotion[2].

Through the promotion of afforestation construction of forest carbon sequestration projects, carbon sequestration projects in highway, not only can achieve the result that absorb carbon dioxide, and the cost is low, the maneuverability is strong, it is now recognized as the most effective way to reduce. Forest carbon sink forest vegetation is carries on the photosynthesis to absorb the carbon dioxide in the atmosphere, fixed and storage process.

According to the study: trees, the average growth 1 cubic meters, can absorb 1.83 tons of carbon dioxide[3]. According to the statistics by forest ecosystem carbon reserves of about 1.115 quadrillion tons, accounting for $46.37 \%$ of the total global terrestrial ecosystem carbon storage[4]. China to carry 
out a large area of afforestation activities, according to the relevant experts and scholars estimated in 1980 to 2005 the 25 years, through afforestation project, the net $\mathrm{CO}_{2}$ uptake amount up to 4.68 million tons. Thus, the ability of forest to absorb carbon significantly, in response to global environmental issues, the forest has a very important role.

\section{The meaning of the low carbon road built carbon sink forest development}

China as a developing country has responsibility and obligation to undertake emission reduction work and with the development of the clean development mechanism (CDM) and the rise of the international carbon trading market, carbon dioxide emissions can in market transactions. Implemented forestry carbon sequestration project, not only can improve the forest ecological system solid ability, and can be absorbed by forests to store carbon dioxide as a kind of trading products, this development of forest carbon sink projects, the implementation of energy-saving emission reduction work has a very good role in promoting.

In the road greening design process of the past, follow the principle of plant landscaping on both sides of the street.With the development of highway transportation, carbon emissions is becoming more and more serious, so people on the highway environment is getting more and more attention. Now in two rows of the highway planting plants, not only the requirements of environmental protection and beautiful, but also higher carbon sequestration capacity to achieve the goal of "zero carbon" highway. How will the content of the carbon sink forest carbon sinks and forestry carbon sink forest in highway construction is an important issue.

Highway forest carbon sequestration project in our country has just started, at present in jiaxing, zhejiang province implemented a national first carbon sink forest highway project, get very good result. In the greening design of hub interchange area, the design concept of forest carbon sink is cited, according to the requirements of forest carbon sequestration project to work in the implementation of the highway afforestation of carbon sink. This for carbon sequestration afforestation project is a great move.

Carbon sink forestation project implementation time is short, in 2006, the pearl river basin in guangxi governance reforestation project is the world's first CDM forestry carbon sequestration project. Forestation project implementation in the field of traffic green carbon sink, rare, the implementation of carbon sink forest road project construction to promote the forestry construction, traffic greening has the very vital significance[5].

Through the research of forest carbon sequestration project road, of trees on both sides of the highway solid carbon research, selection of tree species, forest carbon sequestration of carbon absorption measurement and dynamic monitoring of carries on the discussion, formed a whole set of highway carbon sink forest carbon sink measurement and monitoring technique, for the traffic department provides advice on road greening projects, for the construction of carbon sink forest, building low-carbon highway to give technical guidance.

\section{Highway carbon sink forest research}

Highway carbon sink forest is mainly introduced the principle of forestry carbon sequestration, and forestry ecology, agriculture ecology, statistics, and so on related theory as the foundation, the road on both sides of the green belt plant carbon source, carbon sequestration mechanism and its influence factor research, combined with "project afforestation carbon sinks measurement and monitoring guidelines" formed a on highway forest carbon sink project measurement and monitoring guidelines. This is the forest carbon sequestration is an important part in the field of highway traffic, take another step forward for the construction of low carbon road.

The primary job of carbon sequestration afforestation plant solid carbon ability research, combined with the effects of plant solid carbon factors analysis, establishment of plant carbon sequestration capacity evaluation model. Expressway is located in the area of greening plants (especially the trees )as the research object, the carbon sequestration capacity of each tree species was studied and evaluated, 
and combined with the growth habits of plants, the choice of carbon sink capacity of tree species was planted. On planting density should be reasonable collocation of tree species, take account of stability of plant community ecology system, give full play to the plant's carbon oxygen release function, improve the expressway the carbon sink function of plants.

Construction of highway of forest carbon sinks need stratification of the project area, because of the land within the project boundary may have a very small difference, such as different soil conditions, land use in different ways such as. In the process of carbon measurement and monitoring of sample plot sampling investigation to estimate the change of carbon carbon library, in order to reduce the sampling error and precision of computing project net carbon sink capacity, need for layered project area.

According to the method of forestry carbon sequestration projects division of carbon pool and carbon pool of highway afforestation project should focus on selecting the above ground biomass and underground biomass. Litter carbon storage of carbon pool and dead charcoal base is relatively small, in the calculation, choose not to count. Soil organic carbon library depend on the project of accuracy requirements.

In the afforestation of carbon sinks, need for carbon measurement and monitoring of project. Selected samples, using fixed sample plots and temporary sample plot to measurement and monitoring. To measure the sample area, randomly select at least five representative sample point $1 \mathrm{~m} * 1 \mathrm{~m}$. Choose the ground biomass as carbon sinks for carbon measurement there is harvest method and average method of wood, but the harvest method workload is big, cost is high, destructive, average tree measurement accuracy is not high, so the two kinds of methods are not commonly used. The ground biomass were estimated by allometric growth equation and biomass expansion factor method to estimate. The underground biomass carbon storage Volume is usually used: root cap ratio measuring underground biomass and underground biomass equations. Trees obtained through the method of the above theory, dynamic data of carbon carbon measurement and monitoring model was constructed, for carbon trading with real data.

For the highway forest carbon sequestration project, source of greenhouse gas emissions vehicle emissions exhaust. Afforestation activities caused by source of greenhouse gas emissions may have: transport saplings use vehicles consume the burning of fossil fuels releases greenhouse gases, in afforestation and management activities of applying organic fertilizer plants produce greenhouse gas emissions, the occurrence of accidents, such as implementing fires caused by emissions of greenhouse gases in the process of project, etc. It is the source of greenhouse gas emissions, because of the high technology is difficult, the cost is not each measurement and monitoring is required, but choose measurement and monitoring of the key source of greenhouse gas emissions. For the leak amount forecast, considering the cost factor, seedlings and fertilizer project only for transportation, machinery to measure the carbon loss from soil preparation. Project generated a net amount equal to the change in the project of carbon carbon sink, lose project activities within the project boundaries increased emissions, lose the baseline carbon variation, lose the leak amount of the project. The specific calculation formula is as follows shown[6]:

$$
C_{p r o j, t}=\Delta C_{p r o j, t}-G H G_{E, t}-L K_{t}-\Delta C_{B S L, t}
$$

Type :

$C_{\text {proj, } t}$ The net carbon sink of the project $\mathrm{t}$

$\Delta C_{p r o j, t}$ The change of carbon storage in the project of the year $\mathrm{t}$

$G H G_{E, t}$ Increase in greenhouse gas emissions within the project boundary in the year $\mathrm{t}$

$L K_{t} \quad$ The leakage caused by the project activities in the year $\mathrm{t}$

$\Delta C_{B S L, t}$ Changes in baseline carbon stocks in the first $\mathrm{t}$ years

$\mathrm{t} \quad$ Number of years after the start of the project

Research on carbon sequestration afforestation project highway angle of carbon from the suction of the construction of forest carbon sequestration, a substantial absorption of carbon dioxide to achieve 
emission reduction. This and ordinary afforestation activities differ, because the highway afforestation carbon sequestration project is to enhance sinks and emissions reduction for the purpose and need on tree growth process management, measurement and monitoring of carbon sequestration, and ultimately the formation of highway carbon accounting and monitoring guidelines, so as to provide a theoretical basis for the follow-up of the carbon sequestration in afforestation projects.

\section{The main technical points of the construction of highway carbon sink forest}

Through research, the main technical key point for the construction of highway carbon sink forest is:

(1) The carbon measurement model of different plants.

In the process of the study on the capacity of plant carbon sink, the factors that affect the carbon fixation ability of the plant should be studied, Research. for example plant species, plant growth, leaf area index, season, etc. various kinds of influence factors determine the weight, combined with the impact factors, construction of plant carbon sequestration capacity evaluation model. Due to various factors in different degrees affect carbon absorbing ability of the whole plant, so in the proportion of different factors give must scientific and reasonable, which is an important factor in the impact assessment of different species of carbon sink effect.

For the measurement of carbon storage in biomass carbon pool and need to establish different trees of the allometric equations. Due to carbon sequestration afforestation projects on both sides of the road, selection of plant are more, and each plant established allometric carbon growth model different, so the amount of data collected large. And underground biomass carbon reserves measurement is very difficult, so we choose the root to shoot ratio estimate root biomass, but ratio of below ground biomass of above ground biomass between 0.18 and 0.3 , in constructing the carbon reserves measurement model, ratio of selected is a important task.

(2) The choice of reasonable carbon library

Very high cost is usually in the selected carbon pool, need to analyze carbon net emission sources, but also should measure, monitor and analysis of uncertainty. For example, to select litter, dead matter as carbon Library in the project measurement period, carbon storage change is small, uncertainty, and measurement and monitoring cost is too high, it is not cost effective principle, this we can be conservative ignored. But the selection of carbon pool and must follow the project requirements, the project accuracy is high, usually to all consideration. Therefore, in building a road forest carbon sink projects focus on the ground biomass, underground biomass and soil organic matter of the three carbon pool, and to change Small litter and litter carbon storage, are generally not as measurement point.

If it is necessary to accurately measure the change of carbon reserves, we need to have all of the project boundaries Carbon pool measurement, but such a waste of human resources, financial resources are very huge. The carbon storage of road carbon sequestration projects to measure, in order to save costs, can be in accordance with the project requirements of the accuracy of the conservative selection of carbon library.

(3) Carbon sink metering carbon sink monitoring technology

Construction of highway of forest carbon sinks is an arduous and long-term work, due to measurement and monitoring with many kinds of tree species and continuing a long monitoring period, so the project of forest stratification and sampling design technology is the key technology.

In the process of carbon sequestration afforestation, select tree species and different, need to imitate the natural community environment on the road on both sides of the green belt, of greening plants diversified configuration, according to tree species were stratified planted, of carbon reserves measurement of layered metering and monitoring, to improve the accuracy. In the selected tree species must comply with the following principles: 1 , carbon sequestration road suitable tree principle; 2 , the stability of the ecological system principle; 3, carbon sequestration highway safety comfort; 4 . The principle of economic efficiency.

In the carbon measurement and monitoring technology, need to sample to sample design, according to the general land utilization division of fixed and temporary sample plots were sampled. Lo domain of 
plant carbon measurement and monitoring, hierarchical selection of typical trees like monitoring. How to the forests and kind of hierarchical design is the important content of carbon sequestration measurement and monitoring.

(4) Determination of carbon emission source

Greenhouse gas emissions caused by highway carbon sequestration projects are mainly transport vehicles transporting seedlings, chemical fertilizer, chemical fertilizer, chemical fertilizer, chemical fertilizer, chemical fertilizer, chemical fertilizer, chemical fertilizer, chemical fertilizer, and chemical fertilizer. Fossil fuel, and in afforestation management process to saplings application organic fertilizer, watering, mechanical site preparation and so on. Because these activities will lead to carbon emissions, so in the process of measuring carbon need these into consideration. Afforestation project caused by leakage of the main consideration of the transport combustion of fossil fuel emissions of greenhouse gases, so the need for the project participants and the implementation of the project of reforestation project activities related to the vehicle were recorded.

\section{Conclusions}

Under the environment of global climate warming, build highway forest carbon sink, build low carbon traffic environment is an important issue. Highway construction of carbon sink forests need to first fully understand the concept of forest carbon sink, and then combined with the index of <afforestation project of carbon measurement and monitoring guidelines>, domain of plant planning, to pick out a good solid carbon plant, project baseline determination carbon pool, source of greenhouse gas emissions to determine. At last, the establishment of Road plant carbon sequestration quantification and monitoring model. For the follow-up of the carbon sequestration in afforestation projects provide important theoretical basis and technical guidance.

Highway carbon sink forest project for our country's carbon sequestration research provides a new train of thought, to improve the quality of plants on either side of the highway greening, building carbon sink forest, green low carbon road construction has far-reaching significance.

\section{Acknowledgements}

The paper is support by the following three fund project: Jiangsu Transportation Science and Technology Project "Research on The Slow Traffic Guarantee System" (No. 2014N03-1), Jiangsu University Philosophy and Social Science Research Fund Project "Study on Evaluation System of Innovative City - Taking The Medium and Large Cities of Jiangsu Province for Example" (No. 2014SJB276), Postdoctoral Research Funding Plan of Jiangsu Province (No. 1501147 B).

\section{References}

[1] Lixin Shi . Study on energy consumption and carbon emission of traffic [M]. Beijing: China Economic Publishing House, 2011

[2] Xiaoquan Zhang. Theory and practice of forestry carbon sink project [M]. Beijing: China Forestry Publishing House, 2010

[3] Nuyun Li. China forestry carbon sink [M]. Beijing: China Forestry Publishing House, 2007

[4] Nuyun Li. Measurement of forest carbon sink [M]. Beijing: China Forestry Publishing House, 2010

[5] Xiaoquan Zhang, shuhong Wu. China CDM afforestation and reforestation project guide [M]. Beijing: Chinese Forestry Press, 2006

[6] State Forestry Administration. Guidelines for the measurement and monitoring of carbon sink in 
afforestation projects [M]. Beijing: China Forestry Publishing House, 2008 